\title{
A comparison of the phenolic profile and antioxidant activity of different Cichorium spinosum L. ecotypes
}

\section{Spyridon A Petropoulos, ${ }^{a^{*} \oplus}$ Ângela Fernandes, ${ }^{b}$ Lillian Barros $^{\mathrm{b}}$ and Isabel CFR Ferreira ${ }^{b^{*}}$}

\begin{abstract}
BACKGROUND: Wild greens are considered a rich source of phenolic compounds and antioxidants and an essential part of the so-called Mediterranean diet. In the present study, Cichorium spinosum L. ecotypes, cultivated or collected in situ from wild plants from the eastern Mediterranean, were evaluated regarding their phenolic composition and antioxidant activity.

RESULTS: Significant differences were observed among the various studied ecotypes regarding their phenolic compound content and profile, especially between wild and cultivated ecotypes, as well as the phenolic acid content between commercial products and cultivated plants. The antioxidant activity also varied among the various studied ecotypes and growing conditions, with commercial products having the highest antioxidant activity, whereas wild ecotypes showed lower antioxidant activity.

CONCLUSION: Cichorium spinosum leaves are a rich source of chicoric and 5-O-caffeoylquinic acid, while significant differences in total phenolic acids, flavonoids and phenolic compound content and in antioxidant activity were observed among the studied ecotypes, as well as between the tested growing conditions. According to the results of the present study, further valorization of $C$. spinosum species has great potential, since it could be used as a new alternative species in the food industry.
\end{abstract}

(c) 2017 Society of Chemical Industry

Keywords: antioxidant activity; bioactive compounds; chicoric acid; Cichorium spinosum; phenolic compounds

\section{INTRODUCTION}

Phenolic compounds are secondary metabolites of plants with great importance for various physiological and morphological features, such as defense mechanisms, cell wall structure, interaction with phytohormones, proteins and enzymes, scavenging of free radicals and signaling for gene expression. ${ }^{1}$ Moreover, they contribute significantly to the taste, color, flavor and odor of fruits and vegetables and their contents are essential for antioxidant activity. ${ }^{2}$ There is a great diversity of phenolic compounds within the various plant species, which are classified into many classes according to their chemical structure, namely the number of phenol rings and the binding elements, while the most abundant classes include phenolic acids, flavonoids, tannins, stilbenes and lignans. ${ }^{3,4}$

The antioxidant activity of phenolic compounds is mainly attributed to their ability to react with reactive oxygen and nitrogen species and block the regeneration of new radicals, to chelate the metal ions that are involved in free radicals production, to inhibit various enzymes that induce radical production, and finally to act synergistically with other antioxidants, such as carotenes, tocopherols and ascorbic acid. ${ }^{5}$

Fruit and vegetables are considered a valuable source of phytonutrients and bioactive compounds, and according to various studies their high intake could reduce the risk of many diseases, such as cancer, diabetes and heart disease, and generally improves overall physical condition and health. ${ }^{6-14}$ Moreover, wild edible greens, including many species of the Asteraceae family, are important ingredients of the so-called Mediterranean diet, owing to their high nutritional value and bioactive compound content. ${ }^{15-17}$ The antioxidant activity of wild greens and leafy vegetables may be attributed to several antioxidants or non-antioxidant compounds, as well as to their synergistic effects, since the protective action of the main antioxidants such as vitamins $C$ and $E$, and $\beta$-carotene in intervention trials has not been conclusively confirmed so far. ${ }^{14,18}$

Cichorium spinosum L., a member of the Asteraceae family, is native to the Mediterranean basin and usually grows in coastal areas or plateaus. It is a very common ingredient of various dishes in many Mediterranean countries and a principal component of the so-called Mediterranean diet. ${ }^{19-22}$ The phenolic composition of the main commercially cultivated Cichorium species (C. intybus and $C$. endivia) has been described by many authors, who have

\footnotetext{
Correspondence to: SA Petropoulos, University of Thessaly, School of Agricultural Sciences, Fytokou Street, 38446, N Ionia, Magnissia, Greece, E-mail: fangio57gr@gmail.com; or ICFR Ferreira, Polytechnic Institute of Bragança, Campus de Santa Apolónia, 1172, 5300-253 Bragança, Portugal. E-mail:iferreira@ipb.pt

a Laboratory of Vegetable Production, University of Thessaly, Magnissia, Greece

b Mountain Research Centre (CIMO), ESA, Polytechnic Institute of Bragança, Bragança, Portugal
} 


\begin{tabular}{|llllllll}
\hline \multicolumn{2}{|c|}{ Table 1. } & Details for sampling of Cichorium spinosum ecotypes & & & \\
Sample & Prefecture & Region & Growing conditions & Growing system & Latitude & Longitude & Sampling date \\
\hline 1 & Crete & Chania & Cultivated from seed & Conventional & $35^{\circ} 54^{\prime} 99^{\prime \prime}$ & $24^{\circ} 07^{\prime} 38^{\prime \prime}$ & 6 Jun 2015 \\
2 & Crete & Chania & Commercial product & Organic & $35^{\circ} 43^{\prime} 76^{\prime \prime}$ & $23^{\circ} 94^{\prime} 09^{\prime \prime}$ & $5 \mathrm{Jun} 2015$ \\
3 & Crete & Chania & Commercial product & Conventional & $35^{\circ} 43^{\prime} 76^{\prime \prime}$ & $23^{\circ} 94^{\prime} 09^{\prime \prime}$ & $5 \mathrm{Jun} 2015$ \\
4 & Laconia & Velanidia & Wild & Collected in situ & $36^{\circ} 46^{\prime} 53^{\prime \prime}$ & $23^{\circ} 16^{\prime} 87^{\prime \prime}$ & 14 May 2015 \\
5 & Laconia & Velanidia & Wild & Collected in situ & $36^{\circ} 46^{\prime} 53^{\prime \prime}$ & $23^{\circ} 16^{\prime} 87^{\prime \prime}$ & 14 May 2015 \\
6 & Crete & Chania & Cultivated from seed & Conventional & $35^{\circ} 50^{\prime} 71^{\prime \prime}$ & $24^{\circ} 01^{\prime} 72^{\prime \prime}$ & 6 Jun 2015 \\
\hline
\end{tabular}

detected various phenolic compounds ${ }^{23-35}$; according to Sareedenchai and Zidorn, ${ }^{36}$ phenolic composition varies greatly among the various species of the Cichorieae tribe of the Asteraceae family. For $C$. intybus, the main reported phenolic compounds have been various hydroxycinnamic acid derivatives (including dicaffeoylquinic acids), tartaric acid derivatives, flavonols and flavone glycosides, anthocyanins and sesquiterpene lactones. ${ }^{23-29}$ Similarly, the main detected compounds for C. endivia were hydroxycinnamic acid derivatives, flavonoids (kaempferol glucuronide and kaempferol glucosides), and hydroxyphenyl acetates. ${ }^{30-35}$

So far, there have been reports regarding only the total phenol content of Cretan ecotypes of $C$. spinosum, either from wild plants collected in situ ${ }^{19,20}$ or from cultivated plants grown in hydroponic systems and soilless substrates. ${ }^{21,22}$

In addition, Melliou et al. ${ }^{37}$ studied the phytochemical composition of aerial parts of wild C. spinosum plants collected on Crete island (Greece) and identified four alkylresorcinol derivatives, cichoriol $B$ and a mixture of cichoriol $A, C$ and $D$, and two sesquiterpene lactones, namely lactucopicrin and 3,4-dihydrolactucopicrin, as the main compounds. Further secondary metabolites of $C$. spinosum aerial parts from plants of wild origin (Sicily, Italy) have been reported by Michalska and Kisiel, ${ }^{38}$ who identified four new coumarins and four sesquiterpene lactones. More recently, Petropoulos et al. ${ }^{39}$ reported the phenolic composition of a Cretan ecotype of C. spinosum grown under saline conditions, with chicoric acid and quercetin-3-O-glucuronide being the most abundant phenolic acid and flavonoid, respectively. However, to the best of our knowledge the phenolic composition of $C$. spinosum ecotypes grown under different growing conditions has not been reported so far.

Considering the significant effect of growing conditions and genotype on bioactive compound content and antioxidant activity of leafy vegetables, the aim of the present study was the evaluation of the potential for further exploitation of $C$. spinosum not only for food products but also for pharmaceutical purposes. Therefore, the antioxidant activity and identification of specific phenolic compounds of $C$. spinosum ecotypes from the eastern Mediterranean were determined. Additionally, a comparison between experimentally cultivated and/or commercial products with wild plants collected in situ from their natural habitats regarding their phenolic composition and antioxidant activity was carried out in order to identify the best conditions for increasing phenolic compound content and antioxidative properties.

\section{MATERIALS AND METHODS}

\section{Sampling material and collection areas}

Samples of six ecotypes of Cichorium spinosum L. were evaluated for their phenolic compound content and antioxidant activity. The studied ecotypes were as follows: (a) commercial products obtained from retail supermarkets (samples 2 and 3); (b) ecotypes collected in situ (samples 4 and 5); and (c) plants grown at the farm of the University of Thessaly (samples 1 and 6). Further details of the studied ecotypes are presented in Table 1. Commercial products (samples 2 and 3) were cultivated in Chania region, Greece (Crete island: latitude $35^{\circ} 43^{\prime} 76^{\prime \prime}$, longitude $23^{\circ} 94^{\prime} 09^{\prime \prime}$ ), according to product label, whereas additionally, sample 2 was certified as organic by an official certification body (DIO Inspection and Certification Body, Greece). Samples 4 and 5 were collected in situ from wild plants located in the area of Velanidia municipality, Greece (Laconia Prefecture: latitude $36^{\circ} 46^{\prime} 53^{\prime \prime}$, longitude $23^{\circ} 16^{\prime} 87^{\prime \prime}$ ). For ecotypes 1 and 6, samples were collected from plants grown from seeds in an unheated plastic experimental greenhouse of the University of Thessaly, throughout the growing period of 2014-2015 (late autumn to early spring). For this reason, seeds of the above-mentioned ecotypes ( 1 and 6 ) were collected from the regions described in Table 1, and placed in seed trays containing peat and transplanted at the stage of three leaves in $2 \mathrm{~L}$ pots containing peat (Klassman-Deilmann KTS2) and perlite in a ratio of 2:1 (v/v). For ecotypes 1 and 6, 20 seedlings were transplanted in $2 \mathrm{~L}$ pots (40 plants in total). After transplanting, plants were fertilized via irrigation with nutrient solution containing $300 \mathrm{~g}$ $\mathrm{kg}^{-1} \mathrm{~N}-\mathrm{P}-\mathrm{K}$ throughout the growing season. Harvest took place when rosettes reached marketable size, by collecting the aerial parts from 10 plants of each ecotype. After harvest, the collected plant tissues were divided into three batch samples for further analysis. Commercial products were obtained from retail supermarkets at the same period that harvest of cultivated samples took place. For each product, three $500 \mathrm{~g}$ packages were purchased and samples from each package were considered as replicates for further analysis. Samples from wild ecotypes were collected in situ when their rosettes also reached marketable size, by cutting only the rosettes of leaves without destroying the latent buds. Sampling involved identification of the species, positioning and defining of the sampling units in the areas of interest, considering also the least disturbance of wild populations and the accessibility of the terrain. Seed collections for all samples, except for wild samples (samples 4 and 5) were deposited at the Laboratory of Vegetable Production, University of Thessaly, Greece.

Raw samples of leaves were stored after harvest under deep-freezing conditions $\left(-80^{\circ} \mathrm{C}\right)$ and freeze dried prior to analysis.

\section{Phenolic compound analysis General}

Hydromethanolic extracts were prepared by stirring the dried plant material $(1 \mathrm{~g})$ with $30 \mathrm{~mL}$ methanol-water $(80: 20, \mathrm{v} / \mathrm{v}$, at $25^{\circ} \mathrm{C}$ and $300 \times g$ ) for $1 \mathrm{~h}$ and subsequently filtering through Whatman paper No. 4 filters. The residue was then re-extracted with an additional portion of $30 \mathrm{~mL}$ of the hydromethanolic mixture. 
Table 2. Retention time (Rt), wavelengths of maximum absorption in the visible region $\left(\lambda_{\max }\right)$, mass spectral data and tentative identification of phenolic compounds in Cichorium spinosum leaves

\begin{tabular}{|c|c|c|c|c|c|}
\hline Compound & Rt (min) & $\begin{array}{l}\lambda_{\max } \\
(\mathrm{nm})\end{array}$ & $\begin{array}{l}\text { Molecular ion } \\
{[\mathrm{M}-\mathrm{H}]^{-}(\mathrm{m} / \mathrm{z})}\end{array}$ & $\begin{array}{l}\mathrm{MS}^{2} \\
(\mathrm{~m} / \mathrm{z})\end{array}$ & Tentative identification \\
\hline 1 & 5.1 & 328 & 311 & $179(85), 149(54), 135(100)$ & Caftaric acid \\
\hline 2 & 8.2 & 328 & 353 & $191(100), 179(71), 135(43)$ & 5-O-Caffeoylquinic acid \\
\hline 3 & 14.8 & 330 & 473 & $313(68), 293(83), 219(13), 179(93), 149(100), 135(42)$ & Cis-Chicoric acid \\
\hline 4 & 14.9 & 330 & 473 & $313(68), 293(83), 219(13), 179(93), 149(100), 135(42)$ & Trans-Chicoric acid \\
\hline 5 & 19.5 & 312 & 457 & $295(100), 277(68), 219(26), 179(24), 163(58), 149(8)$ & Coutaric acid hexoside \\
\hline 6 & 19.9 & 358 & 477 & $301(100)$ & Quercetin-3-O-glucuronide \\
\hline 7 & 20.3 & 350 & 461 & $285(100)$ & Kaempferol-O-glucuronide \\
\hline 8 & 21.2 & 310 & 295 & 219(27), 179(5), 163(22), 149(5), 135(11) & Coutaric acid \\
\hline 9 & 21.2 & 330 & 325 & 193(100), 134(98) & Fertaric acid \\
\hline 10 & 22.3 & 356 & 505 & $463(10), 301(100)$ & Quercetin-7-O-(6"'-O-acetyl)glucoside \\
\hline 11 & 22.6 & 328 & 515 & 353()$, 191(98), 179(77), 161(4), 135(22)$ & 3,5-O-Dicaffeoylquinic acid \\
\hline 12 & 23.5 & 348 & 593 & $285(100)$ & Kaempferol-3-O-rutinoside \\
\hline 13 & 24.4 & 348 & 461 & $285(100)$ & Kaempferol-3-O-glucuronide \\
\hline 14 & 25.2 & 336 & 445 & $269(100)$ & Apigenin-O-glucuronide \\
\hline 15 & 25.5 & 358 & 491 & $315(100)$ & Isorhamnetin-3-O-glucuronide \\
\hline 16 & 26.9 & 338 & 489 & $285(100)$ & Kaempferol-3-O-(6"-O-acetyl)glucoside \\
\hline 17 & 28.0 & 358 & 519 & $315(100)$ & Isorhamnetin-3-O-(6" -O-acetyl)glucoside \\
\hline
\end{tabular}

The combined extracts were evaporated under reduced pressure (Büchi R-210, rotary evaporator, Flawil, Switzerland) until complete removal of methanol, and afterwards the aqueous phase was frozen and lyophilized (FeeeZone 4.5, Labconco, Kansas City, MO, USA). The extracts were redissolved in methanol-water $(80: 20, \mathrm{v} / \mathrm{v})$ at a final concentration of $5 \mathrm{~g} \mathrm{~L}^{-1}$, filtered through a $0.45 \mu \mathrm{m}$ Whatman syringe filter and transferred to an amber high-performance liquid chromatography vial for further determination of the phenolic composition.

Analysis of phenolic compounds was carried out by liquid chromatography-diode array detection-electrospray ionization-multistage mass spectrometry (Dionex Ultimate 3000 UPLC instrument, Thermo Scientific, San Jose, CA, USA,) equipped with a diode array detector and coupled to a mass detector, following a procedure previously reported by Petropoulos et $a l .{ }^{40}$ Phenolic compounds were identified by comparison of commercial standards when available or by tentative methods using reported data from the literature. Calibration curves were created in order to obtain quantification results and were based on the UV signal of each available standard. When no commercial standard was available, a similar compound from the same phenolic group was used as a standard. Results were expressed as grams per kilogram dry extract.

\section{Antioxidant activity assays}

The above-mentioned dry extracts were redissolved in methanol-water $(80: 20, v / v)$ for submission to distinct in vitro antioxidant activity assays, at a final concentration of $20 \mathrm{~g} \mathrm{~L}^{-1}$ and further diluted to different concentrations.

2,2-Diphenyl-1-picrylhydrazyl (DPPH) radical-scavenging activity was evaluated using an ELX800 microplate reader (Bio-Tek Instruments, Inc., Winooski, VT, USA), and calculated as a percentage of DPPH discoloration using the formula $\left[\left(A_{\mathrm{DPPH}}-A_{\mathrm{S}}\right) / A_{\mathrm{DPPH}}\right] \times 100$, where $A_{\mathrm{S}}$ is the absorbance of the solution containing the sample at $515 \mathrm{~nm}$ and $A_{\mathrm{DPPH}}$ is the absorbance of the DPPH solution. Reducing power was evaluated by the capacity to convert $\mathrm{Fe}^{3+}$ to $\mathrm{Fe}^{2+}$, measuring the absorbance at $690 \mathrm{~nm}$ in the microplate reader mentioned above. Inhibition of $\beta$-carotene bleaching was evaluated though the $\beta$-carotene/linoleate assay; the neutralization of linoleate free radicals avoids $\beta$-carotene bleaching, which is measured by the formula: $\beta$-carotene absorbance after $2 \mathrm{~h}$ of assay/initial absorbance) $\times 100$. Lipid peroxidation inhibition in porcine brain homogenates was evaluated by the decrease in thiobarbituric acid reactive substances (TBARS); color intensity of malondialdehyde-thiobarbituric acid (MDA-TBA) was measured by its absorbance at $532 \mathrm{~nm}$; inhibition ratio (\%) was calculated using the following formula: $[(A-B) / A] \times 100 \%$, where $A$ and $B$ are the absorbance of the control and the sample solution, respectively. ${ }^{39}$ The results were expressed in $\mathrm{EC}_{50}$ values (sample concentration providing $50 \%$ of antioxidant activity or 0.5 of absorbance in the reducing power assay) for antioxidant activity, and Trolox was used as a positive control.

\section{Statistical analysis}

For all the analyses, three samples were analyzed for each treatment and all of the assays were carried out in triplicate $(n=9)$. The results were expressed as mean values and standard deviations (SD). Statistical analysis of data was applied using SPSS v. 22.0 program (IBM Corp., Armonk, NY, USA) through a one-way analysis of variance (ANOVA) while, for means where a statistical difference was detected, means comparisons were carried out using Tukey's HSD test $(P=0.05)$.

\section{RESULTS AND DISCUSSION}

The results related to sample 1 (antioxidant activity and composition of phenolic compounds in Tables 3 and 4) have been previously published by the same authors, ${ }^{40}$ since this ecotype was common in both experiments and all the ecotypes in the present study received the same treatment as the control treatment of the previously published research. Therefore, all the data referring to sample 1 have been excluded and are appropriately cited in the text and the corresponding tables. 
Table 3. Phenolic compound quantification ( $\mathrm{kg}^{-1} \mathrm{dry}$ extract) in the studied Cichorium spinosum ecotypes

\begin{tabular}{|c|c|c|c|c|c|c|}
\hline Peak & Phenolic compound & Sample $2^{\mathrm{a}}$ & Sample 3 & Sample 4 & Sample 5 & Sample 6 \\
\hline 1 & Caftaric acid & $0.49 \pm 0.01$ & $1.50 \pm 0.01$ & $0.30 \pm 0.02$ & $0.84 \pm 0.03$ & $2.39 \pm 0.02$ \\
\hline 2 & 5-O-Caffeoylquinic acid & $2.40 \pm 0.02$ & $5.29 \pm 0.05$ & $1.75 \pm 0.01$ & $1.77 \pm 0.03$ & $9.46 \pm 0.03$ \\
\hline 3 & Cis-Chicoric acid & $13.31 \pm 0.05$ & $17.4 \pm 0.2$ & $4.47 \pm 0.01$ & $7.06 \pm 0.03$ & $16.0 \pm 0.2$ \\
\hline 4 & Trans-Chicoric acid & $13.45 \pm 0.06$ & $16.2 \pm 0.5$ & $0.082 \pm 0.001$ & $0.082 \pm 0.001$ & $15.1 \pm 0.1$ \\
\hline 5 & Coutaric acid hexoside & $0.71 \pm 0.02$ & $1.04 \pm 0.04$ & $0.037 \pm 0.001$ & $0.16 \pm 0.01$ & $0.57 \pm 0.02$ \\
\hline 6 & Quercetin-3-O-glucuronide & $5.57 \pm 0.03$ & $5.57 \pm 0.01$ & $1.070 \pm 0.001$ & $1.47 \pm 0.02$ & $1.04 \pm 0.01$ \\
\hline 7 & Kaempferol-O-glucuronide & $6.18 \pm 0.02$ & $3.80 \pm 0.01$ & $0.64 \pm 0.01$ & $0.75 \pm 0.01$ & $0.53 \pm 0.01$ \\
\hline 8 & Coutaric acid & nd & nd & nd & nd & nd \\
\hline 9 & Fertaric acid & $2.45 \pm 0.05$ & $3.27 \pm 0.05$ & $0.36 \pm 0.01$ & $1.01 \pm 0.01$ & $6.45 \pm 0.04$ \\
\hline 10 & Quercetin-7-O-(6"-O-acetyl)glucoside & $0.56 \pm 0.02$ & $0.876 \pm 0.01$ & $\operatorname{tr}$ & $0.204 \pm 0.002$ & $0.53 \pm 0.03$ \\
\hline 11 & 3,5-O-Dicaffeoylquinic acid & $1.37 \pm 0.03$ & $1.71 \pm 0.01$ & $0.79 \pm 0.01$ & $1.99 \pm 0.01$ & $2.40 \pm 0.02$ \\
\hline 12 & Kaempferol-3-O-rutinoside & $0.094 \pm 0.002$ & $0.070 \pm 0.003$ & $\operatorname{tr}$ & $0.019 \pm 0.004$ & $\operatorname{tr}$ \\
\hline 13 & Kaempferol-3-O-glucuronide & $3.13 \pm 0.02$ & $3.35 \pm 0.05$ & $0.90 \pm 0.01$ & $1.02 \pm 0.01$ & $0.62 \pm 0.01$ \\
\hline 14 & Apigenin-7-O-glucuronide & $1.26 \pm 0.08$ & $1.31 \pm 0.01$ & $0.24 \pm 0.01$ & $0.16 \pm 0.01$ & $0.66 \pm 0.02$ \\
\hline 15 & Isorhamnetin-3-O-glucuronide & $2.194 \pm 0.09$ & $2.63 \pm 0.04$ & $0.237 \pm 0.004$ & $0.26 \pm 0.01$ & $0.11 \pm 0.01$ \\
\hline 16 & Kaempferol-3-O-(6"-O-acetyl)glucoside & $0.54 \pm 0.04$ & $0.84 \pm 0.01$ & $0.12 \pm 0.01$ & $0.38 \pm 0.01$ & $0.26 \pm 0.01$ \\
\hline \multirow[t]{4}{*}{17} & Isorhamnetin-3-O-(6"'-O-acetyl)glucoside & $0.17 \pm 0.03$ & $0.13 \pm 0.02$ & $0.032 \pm 0.002$ & $0.140 \pm 0.002$ & $0.925 \pm 0.004$ \\
\hline & Total phenolic acids & $34.2 \pm 0.2 c$ & $46 \pm 1 b$ & $7.79 \pm 0.01 \mathrm{e}$ & $12.9 \pm 0.1 \mathrm{~d}$ & $52.3 \pm 0.3 a$ \\
\hline & Total flavonoids & $19.7 \pm 0.1 a$ & $18.6 \pm 0.2 b$ & $3.24 \pm 0.04 d$ & $4.40 \pm 0.02 c$ & $4.7 \pm 0.1 c$ \\
\hline & Total phenolic compounds & $53.9 \pm 0.1 c$ & $65 \pm 1 a$ & $11.04 \pm 0.05 e$ & $17.3 \pm 0.1 d$ & $57.0 \pm 0.1 b$ \\
\hline
\end{tabular}

tr, trace; nd, not detected. In each row, different letters mean significant statistical differences between samples $(P<0.05)$.

a Data regarding sample 1 have been previously reported by the authors. ${ }^{40}$

Table 4. Antioxidant properties of the studied Cichorium spinosum ecotypes

$$
\mathrm{EC}_{50} \text { values }\left(\mathrm{g} \mathrm{L}^{-1}\right)
$$

\begin{tabular}{|lcccc|}
\cline { 2 - 3 } Sa $^{\mathrm{a}}$ & DPPH radical-scavenging activity & Reducing power & $\beta$-carotene bleaching inhibition & TBARS inhibition \\
\hline 2 & $0.35 \pm 0.01 \mathrm{c}$ & $0.15 \pm 0.01 \mathrm{c}$ & $0.44 \pm 0.06 \mathrm{c}$ & $0.02 \pm 0.01 \mathrm{~d}$ \\
3 & $0.27 \pm 0.01 \mathrm{~d}$ & $0.12 \pm 0.01 \mathrm{~d}$ & $0.29 \pm 0.01 \mathrm{~d}$ & $0.02 \pm 0.01 \mathrm{~d}$ \\
4 & $0.86 \pm 0.01 \mathrm{~b}$ & $0.28 \pm 0.01 \mathrm{~b}$ & $0.48 \pm 0.02 \mathrm{~b}$ & $0.05 \pm 0.01 \mathrm{~b}$ \\
5 & $2.92 \pm 0.12 \mathrm{a}$ & $0.76 \pm 0.01 \mathrm{a}$ & $0.89 \pm 0.02 \mathrm{a}$ & $0.14 \pm 0.01 \mathrm{a}$ \\
6 & $0.37 \pm 0.02 \mathrm{c}$ & $0.15 \pm 0.01 \mathrm{c}$ & $0.45 \pm 0.02 \mathrm{bc}$ & $0.03 \pm 0.01 \mathrm{c}$ \\
\hline
\end{tabular}

Antioxidant activity was expressed as $\mathrm{EC}_{50}$ values, which means that higher values correspond to lower reducing power or antioxidant potential. $\mathrm{EC}_{50}$ : Extract concentration corresponding to $50 \%$ antioxidant activity or 0.5 absorbance in reducing power assay. Trolox EC 50 values: $0.041 \mathrm{~g} \mathrm{~L}^{-1}$ (reducing power), $0.042 \mathrm{~g} \mathrm{~L}^{-1}$ (DPPH scavenging activity), $0.018 \mathrm{~g} \mathrm{~L}^{-1}$ ( $\beta$-carotene bleaching inhibition) and $0.023 \mathrm{~g} \mathrm{~L}^{-1}$ (TBARS inhibition). In each column, different letters mean significant differences between samples $(P<0.05)$.

a Data regarding sample 1 have been previously reported by the authors. ${ }^{40}$

The phenolic compounds profile of C. spinosum hydromethanolic extracts are presented in Table 2. These samples were characterized by the presence of 17 phenolic compounds, from which eight were classified as phenolic acids and nine as flavonoid glycoside derivatives (Table 2). With the exception of chicoric acid isomer II (compound 4), kaempferol-O-glucuronide (compound 7), 3,5-O-dicaffeoylquinic acid (compound 11), apigenin-7-O-glucuronide (compound 14), isorhamnetin-3-O-glucuronide (compound 15) and isorhamnetin-3-O-(6"-O-acetyl) glucoside (compound 17), the remaining 11 compounds were reported by us in a previous study using different C. spinosum plants (apart from sample 1, which was common in both experiments) grown under saline conditions. ${ }^{40}$ Compound $4\left([\mathrm{M}-\mathrm{H}]^{-}\right.$at $\left.\mathrm{m} / \mathrm{z} 473\right)$ presented similar UV-visible and mass spectra to compound 3, being tentatively identified as trans-chicoric acid. This phenolic acid has been previously reported in many studies of $C$. intybus, ${ }^{23,27-30,41}$ as well as in a previous study performed by us using different C. spinosum plants grown under saline conditions. ${ }^{40}$ Thus the two isoforms have only been reported in C. intybus leaves by Carazzone et al..$^{23}$

The pseudomolecular ion of compounds $7\left([\mathrm{M}-\mathrm{H}]^{-}\right.$at $\left.m / z 461\right)$, $14\left([\mathrm{M}-\mathrm{H}]^{-}\right.$at $\left.m / z 445\right)$ and $15\left([\mathrm{M}-\mathrm{H}]^{-}\right.$at $\mathrm{m} / z$ 491) were coherent with a kaempferol, apigenin and isorhamnetin glucuronide, respectively. With the exception of compound $\mathbf{7}$, for which no information about the location of the sugar moiety on the aglycone could be obtained, compounds 14 and 15 were identified as apigenin-7-O-glucuronide and isorhamnetin-3-O-glucuronide, respectively. The presence of glucuronide derivatives has been previously reported by us in this species, ${ }^{40}$ as also in C. intybus leaves. ${ }^{23}$ Compound $17\left([\mathrm{M}-\mathrm{H}]^{-}\right.$at $m / z$ 519) was tentatively identified taking into account the findings reported by Carazzone et al..$^{23}$ and Petropoulos et al. ${ }^{40}$ Finally, compound $11\left([\mathrm{M}-\mathrm{H}]^{-}\right.$at $\mathrm{m} / \mathrm{z} 515$ ) showed a fragmentation pattern with a base peak at

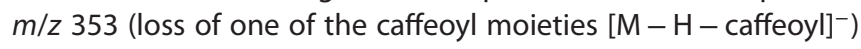


Table 5. Correlations established between total phenolic acids, flavonoids and total phenolic compounds, and antioxidant activity $\mathrm{EC}_{50}$ values of the studied Cichorium spinosum ecotypes

\begin{tabular}{|c|c|c|c|c|c|c|c|c|}
\hline & \multirow{2}{*}{\multicolumn{2}{|c|}{$\begin{array}{c}\text { DPPH scavenging activity } \\
\left(\mathrm{mg} \mathrm{mL}^{-1}\right)\end{array}$}} & \multirow{2}{*}{\multicolumn{2}{|c|}{$\begin{array}{c}\text { Reducing power } \\
\left(\mathrm{mg} \mathrm{mL}^{-1}\right)\end{array}$}} & \multirow{2}{*}{\multicolumn{2}{|c|}{$\frac{\beta \text {-carotene bleaching inhibition }}{\left(\mathrm{mg} \mathrm{mL}^{-1}\right)}$}} & \multirow{2}{*}{\multicolumn{2}{|c|}{$\begin{array}{c}\text { TBARS inhibition } \\
\left(\mathrm{mg} \mathrm{mL}^{-1}\right)\end{array}$}} \\
\hline & & & & & & & & \\
\hline & Linear equation & $R^{2}$ & Linear equation & $R^{2}$ & Linear equation & $R^{2}$ & Linear equation & $R^{2}$ \\
\hline $\begin{array}{l}\text { Total phenolic } \\
\text { acids ( } \mathrm{mg} \mathrm{g}^{-1} \\
\text { extract) }\end{array}$ & $y=-11.662 x+40.51$ & $R^{2}=0.4202$ & $y=-47.977 x+42.726$ & $R^{2}=0.4047$ & $y=-49.563 x+56.577$ & $R^{2}=0.3994$ & $y=-246.05 x+44.377$ & $R^{2}=0.4299$ \\
\hline $\begin{array}{l}\text { Total flavonoids } \\
\text { (mg g } \\
\text { extract) }\end{array}$ & $y=-3.8729 x+12.511$ & $R^{2}=0.2309$ & $y=-15.001 x+12.984$ & $R^{2}=0.1972$ & $y=-22.413 x+21.135$ & $R^{2}=0.4069$ & $y=-111.33 x+15.622$ & $R^{2}=0.4385$ \\
\hline $\begin{array}{l}\text { Total phenolic } \\
\text { compounds } \\
\text { (mg g } \\
\text { extract) }\end{array}$ & $y=-15.535 x+53.021$ & $R^{2}=0.4512$ & $y=-62.978 x+55.71$ & $R^{2}=0.4220$ & $y=-71.976 x+77.713$ & $R^{2}=0.5096$ & $y=-357.38 x+60$ & $R^{2}=0.5487$ \\
\hline
\end{tabular}

and a subsequent fragmentation of this ion yielded the same fragments as 5-O-caffeoylquinic acid at $\mathrm{m} / \mathrm{z} 191,179$ and 135, being tentatively assigned as 3,5-O-dicaffeoylquinic acid. This compound has also been previously reported by Carazzone et al. ${ }^{23}$ The last authors and Innocenti et al. ${ }^{31}$ also revealed the presence of other caffeoyl derivatives in several varieties of $C$. intybus. However, to the best of our knowledge, 3,5-O-dicaffeoylquinic acid is reported for the first time for the aerial parts of $C$. spinosum.

Phenolic acids were the most abundant phenolic compounds for all the studied ecotypes, accounting for $63.4-70.7 \%$ of total phenolic compounds for commercially cultivated ecotypes, while for wild and experimentally cultivated ecotypes the corresponding amount was approximately $70 \%$ and $90 \%$ of total phenolic compounds, respectively (Table 3 ). The abundance of phenolic acids with comparison to flavonoids in C. intybus and C. endivia has been previously reported by Ferioli et al. ${ }^{30}$ and Filippo D'Antuono et al. ${ }^{32}$; however, their proportional content showed significant variation between the studied accessions of chicory and endive. ${ }^{30}$ The main phenolic compounds detected in the studied samples were cis- and trans-chicoric acid, although their content showed a great variation between the studied ecotypes. More specifically, the wild ecotypes (samples 4 and 5) had lower amounts of chicoric acid isomers compared to cultivated ecotypes and especially sample 3 (conventional commercial ecotype), which had the highest amount. Caftaric, 5-O-caffeoylquinic, fertaric and 3,5-O-dicaffeoylquinic acids were detected in higher amounts in sample 6, whereas the lowest amounts were detected in wild ecotype (sample 4).

The main flavonoids detected in various contents in the studied samples were kaempferol-O-glucuronide and quercetin-3-O-glucuronide, whereas kaempferol-3-O-glucoronide and isorhamnetin-3-O-glucuronide were detected in lower amounts (Table 3). These compounds have already been reported for other Cichorium species, such as $C$. intybus and $C$. endivia cultivars and accessions, ${ }^{26,30,32}$ and $C$. spinosum plants grown from wild seeds, ${ }^{40}$ whereas according to Sareedenchai and Zidorn ${ }^{36}$ the flavonoid composition could be a useful means for chemosystematic taxonomy within the Cichorieae tribe of the Asteraceae family. The studied commercial ecotypes (samples 2 and 3 ) had the highest content in flavonoid compounds and consequently in total flavonoids, comparing to either the wild ecotypes (samples 4 and 5 ) or the cultivated ecotypes evaluated in the present study and a previous report by us (samples 1 and 6$),{ }^{40}$ whereas sample 6 had the highest content of isorhamnetin-3-O-(6" -O-acetyl)glucoside.
Antioxidant activity differed significantly among the various studied ecotypes for all the tested assays, with the conventionally cultivated commercial ecotype (sample 3 ) showing the highest antioxidant activity compared to the other ecotypes (Table 4). Conforti et al., ${ }^{7}$ Dalar and Konczak $^{28}$ and Lavelli ${ }^{42}$ have also reported the high antioxidant activity of aqueous and hydromethanolic extracts of chicory (C. intybus), while Rossetto et al..$^{27}$ confirmed the high antioxidant activity of various red chicory cultivars (C. intybus) through peroxyl radical trapping capacity and efficiency. Moreover, Papetti et al. ${ }^{43}$ suggested that only high-molecular-weight phenolic compounds possess strong antioxidant activity, whereas compounds with low molecular weight act mostly as pro-oxidants. This could be the case in the present study, where sample 3 has a higher content of high-molecular-weight phenolic compounds, such as chicoric acid, isorhamnetin-3-O-glucuronide and kaempferol-3-O-(6"-O-acetyl) glucoside, among others, compared to the other studied samples.

Negative linear correlations were observed between phenolic acids, flavonoids and total phenolic compound content, and the $\mathrm{EC}_{50}$ values of the tested antioxidant activity assays for all the studied ecotypes, indicating that higher content of phenolic compounds result in higher antioxidant activity (Table 5 ). However, the low values of determination coefficients $\left(R^{2}\right)$ do not suggest significant correlations between the studied parameters, which may be attributed to secondary metabolites that could not be detected in the present study, such as sesquiterpene lactones, antioxidant vitamins and glutathione. ${ }^{22,35,38}$

Regarding the growing conditions and cultivation practices, significant differences were detected between wild and cultivated plants, as well as between conventionally and organically produced products, with wild ecotypes having significantly lower amounts of phenolic acids and flavonoids and consequently of total phenolic compounds, compared to cultivated plants. According to Williams et al., ${ }^{44}$ many factors may affect phenolic composition in plants, including the genotype (cultivar), growing conditions and soil properties, while Sinkovič et al. ${ }^{29}$ have reported a significant effect of fertilizer type (organic or conventional) on phenolic profile of $C$. intybus leaves. Similar results have been reported by Morales et al. ${ }^{45}$ for wild C. intybus plants, while Spina et al. ${ }^{46}$ detected significant differences in flavonoid content and total phenolic compounds between wild ecotypes and cultivated C. intybus plants. However, the fact that in the study of Spina et al. ${ }^{46}$ both wild (plants grown from wild seeds) and cultivated ecotypes 
were cultivated under the same conditions suggests that genotype has an important effect on phenolic content of aerial parts, which has also been confirmed by Ferioli et al., ${ }^{30}$ who reported a significant variation in phenolics content among various accessions of chicory. Therefore, harvesting of wild plants cannot ensure higher quality per se in terms of phenolic compound content, and commercial production has to be further exploited and expanded in order to produce products of high quality and added value. In addition, the fact that $C$. spinosum is usually found in rocky and hard-to-reach areas, which renders hand-picking laborious and increases the time needed from harvest to consumption, as well as the perishable texture of leafy vegetables such as Cichorium species, could result in a significant decrease of quality in terms of total phenolic compounds and antioxidant activity. ${ }^{42}$

\section{CONCLUSIONS}

Chicorium spinosum phenolic compounds consist mainly of chicoric acid and 5-O-caffeoylquinic acid, while significant differences were observed among the studied ecotypes, as well as between the growing conditions (wild and cultivated plants) regarding phenolic composition (phenolic acids and flavonoids) and antioxidant activity. Moreover, no significant differences were observed between the studied conventional and organic commercial products regarding phenolic compounds and antioxidant activity. Wild ecotypes of the present study had lower content of total phenolic compounds than cultivated ones, whereas commercial products were very rich in flavonoids, especially in kaempferol-3-O-glucuronide, isorhamnetin-3-O-glucuronide and apigenin-O-glucuronide, compared to the other ecotypes (wild and cultivated). Therefore, commercial cultivation of $C$. spinosum (either conventional or organic) should be encouraged since it ensures higher content of phenolic compounds and antioxidant activity and minimizes the danger of genetic erosion from irrational harvesting of wild plants. Moreover, the prospect of using this species for other than human food purposes should be further investigated in various growing systems and cultivation practices.

\section{REFERENCES}

1 Pérez-Gregorio MR, Regueiro J, Simal-Gándara J, Rodrigues AS and Almeida DPF, Increasing the added-value of onions as a source of antioxidant flavonoids: a critical review. Crit Rev Food Sci Nutr 54:1050-1062 (2014).

2 Wang B, Huang Q, Venkitasamy C, Chai H, Gao H, Cheng N et al., Changes in phenolic compounds and their antioxidant capacities in jujube (Ziziphus jujuba Miller) during three edible maturity stages. LWT - Food Sci Technol 66:56-62 (2016).

3 Balasundram N, Sundram K and Samman S, Phenolic compounds in plants and agri-industrial by-products: antioxidant activity, occurrence, and potential uses. Food Chem 99:191-203 (2006).

4 Ignat I, Volf I and Popa VI, A critical review of methods for characterisation of polyphenolic compounds in fruits and vegetables. Food Chem 126:1821-1835 (2011).

5 Khasawneh M, Elwy HM and Fawzi NM, Antioxidant activity and lipoxygenase inhibitory effect of Caralluma arabica and related polyphenolic constituents. Am J Plant Sci 5:1623-1631 (2014).

6 Conforti F, Sosa S, Marrelli M, Menichini F, Statti GA, Uzunov D et al., In vivo anti-inflammatory and in vitro antioxidant activities of Mediterranean dietary plants. J Ethnopharmacol 116:144-151 (2008).

7 Conforti F, Sosa S, Marrelli M, Menichini F, Statti GA, Uzunov D et al., The protective ability of Mediterranean dietary plants against the oxidative damage: the role of radical oxygen species in inflammation and the polyphenol, flavonoid and sterol contents. Food Chem 112:587-594 (2009).

8 Martins D, Barros L, Carvalho AM and Ferreira ICFR, Nutritional and in vitro antioxidant properties of edible wild greens in Iberian Peninsula traditional diet. Food Chem 125:488-494 (2011).
9 Prior RL, Fruits and vegetables in the prevention of cellular oxidative damage. Am J Clin Nutr 78(3 Suppl):570-578 (2003).

10 Saleem A, Husheem M, Härkönen P and Pihlaja K, Inhibition of cancer cell growth by crude extract and the phenolics of Terminalia chebula Retz. fruit. J Ethnopharmacol 81:327-336 (2002).

11 Khanam UKS, Oba S, Yanase E and Murakami Y, Phenolic acids, flavonoids and total antioxidant capacity of selected leafy vegetables. J Funct Foods 4:979-987 (2012).

12 Ismail A, Marjan ZM and Foong CW, Total antioxidant activity and phenolic content in selected vegetables. Food Chem 87:581-586 (2004).

13 Jiménez-Aguilar DM and Grusak MA, Evaluation of minerals, phytochemical compounds and antioxidant activity of Mexican, Central American, and African green leafy vegetables. Plant Foods Hum Nutr 70:357-364 (2015).

14 Deng GF, Lin X, Xu XR, Gao LL, Xie JF and Li H-B, Antioxidant capacities and total phenolic contents of 56 vegetables. J Funct Foods 5:260-266 (2013).

15 Turner NJ, Łuczaj ŁJ, Migliorini P, Pieroni A, Dreon AL, Sacchetti LE et al., Edible and tended wild plants, traditional ecological knowledge and agroecology. CRC Crit Rev Plant Sci 30:198-225 (2011).

16 Nebel S, Pieroni A and Heinrich M, Ta chórta: wild edible greens used in the Graecanic area in Calabria, Southern Italy. Appetite 47:333-342 (2006).

17 González-Tejero MR, Casares-Porcel M, Sánchez-Rojas CP, Ramiro-Gutiérrez JM, Molero-Mesa J, Pieroni A et al., Medicinal plants in the Mediterranean area: synthesis of the results of the project Rubia. J Ethnopharmacol 116:341 - 357 (2008).

18 Simopoulos AP, Omega-3 fatty acids and antioxidants in edible wild plants. Biol Res 37:263-277 (2004).

19 Vardavas Cl, Majchrzak D, Wagner KH, Elmadfa I and Kafatos A, The antioxidant and phylloquinone content of wildly grown greens in Crete. Food Chem 99:813-821 (2006).

20 Zeghichi S, Kallithraka S, Simopoulos AP and Kypriotakis Z, Nutritional composition of selected wild plants in the diet of Greece. World Rev Nutr Diet 91: 22-40 (2003).

21 Klados E and Tzortzakis N, Effects of substrate and salinity in hydroponically grown Cichorium spinosum. J Soil Sci Plant Nutr 14:211-222 (2014).

22 Zeghichi S, Kallithraka S and Simopoulos AP, Nutritional composition of Molokhia (Corchorus olitorius) and Stamnagathi (Cichorium spinosum). World Rev Nutr Diet 91:1-21 (2003).

23 Carazzone C, Mascherpa D, Gazzani G and Papetti A, Identification of phenolic constituents in red chicory salads (Cichorium intybus) by high-performance liquid chromatography with diode array detection and electrospray ionisation tandem mass spectrometry. Food Chem 138:1062-1071 (2013).

24 Heimler D, Isolani L, Vignolini P and Romani A, Polyphenol content and antiradical activity of Cichorium intybus L. from biodynamic and conventional farming. Food Chem 114:765-770 (2009).

25 Graziani G, Ferracane R, Sambo P, Santagata S, Nicoletto C and Fogliano $\mathrm{V}$, Profiling chicory sesquiterpene lactones by high resolution mass spectrometry. Food Res Int 67:193-198 (2015).

26 DuPont MS, Mondin Z, Williamson G and Price KR, Effect of variety, processing, and storage on the flavonoid glycoside content and composition of lettuce and endive. J Agric Food Chem 48:3957-3964 (2000).

27 Rossetto M, Lante A, Vanzani P, Spettoli P, Scarpa M and Rigo A, Red chicories as potent scavengers of highly reactive radicals: a study on their phenolic composition and peroxyl radical trapping capacity and efficiency. J Agric Food Chem 53:8169-8175 (2005).

28 Dalar A and Konczak I, Cichorium intybus from Eastern Anatolia: phenolic composition, antioxidant and enzyme inhibitory activities. Ind Crops Prod 60:79-85 (2014).

29 Sinkovič L, Demšar L, Žnidarčič D, Vidrih R, Hribar J and Treutter D, Phenolic profiles in leaves of chicory cultivars (Cichorium intybus L.) as influenced by organic and mineral fertilizers. Food Chem 166:507-513 (2015).

30 Ferioli F, Manco MA and D'Antuono LF, Variation of sesquiterpene lactones and phenolics in chicory and endive germplasm. J Food Compos Anal 39:77-86 (2015).

31 Innocenti M, Gallori S, Giaccherini C, leri F, Vincieri FF and Mulinacci $\mathrm{N}$, Evaluation of the phenolic content in the aerial parts of different varieties of Cichorium intybus L. J Agric Food Chem 53:6497-6502 (2005). 
32 Filippo D'Antuono L, Ferioli F and Manco MA, The impact of sesquiterpene lactones and phenolics on sensory attributes: an investigation of a curly endive and escarole germplasm collection. Food Chem 199:238-245 (2016).

33 Mascherpa D, Carazzone C, Marrubini G, Gazzani G and Papetti A, Identification of phenolic constituents in Cichorium endivia var. crispum and var. latifolium salads by high-performance liquid chromatography with diode array detection and electrospray ionization tandem mass spectrometry. J Agric Food Chem 60:12142-12150 (2012).

34 Khalil HE and Kamel MS, Phytochemical and biological studies of Cichorium endivia L. leaves. J Pharm Sci Res 7:509-513 (2015).

35 Kisiel W and Michalska K, Sesquiterpenoids and phenolics from roots of Cichorium endivia var. crispum. Fitoterapia 77:354-357 (2006).

36 Sareedenchai V and Zidorn C, Flavonoids as chemosystematic markers in the tribe Cichorieae of the Asteraceae. Biochem Syst Ecol 38:935-957 (2010).

37 Melliou E, Magiatis P and Skaltsounis AL, Alkylresorcinol derivatives and sesquiterpene lactones from Cichorium spinosum. J Agric Food Chem 51:1289-1292 (2003).

38 Michalska Kand Kisiel W, Further sesquiterpene lactones and phenolics from Cichorium spinosum. Biochem Syst Ecol 35:714-716 (2007).

39 Petropoulos SA, Fernandes Â, Barros L, Ferreira ICFR and Ntatsi G, Morphological, nutritional and chemical description of 'Vatikiotiko', an onion local landrace from Greece. Food Chem 182:156-163 (2015).

40 Petropoulos SA, Levizou E, Ntatsi G, Fernandes Â, Petrotos K, Akoumianakis $\mathrm{K}$ et al., Salinity effect on nutritional value, chemical composition and bioactive compounds content of Cichorium spinosum L. Food Chem 214:129-136 (2017).

41 Juśkiewicz J, Zduńczyk Z, Zary-Sikorska E, Król B, Milala J and Jurgoński A, Effect of the dietary polyphenolic fraction of chicory root, peel, seed and leaf extracts on caecal fermentation and blood parameters in rats fed diets containing prebiotic fructans. Br J Nutr 105:710-720 (2011).

42 Lavelli V, Antioxidant activity of minimally processed red chicory (Cichorium intybus L.) evaluated in xanthine oxidase-, myeloperoxidase-, and diaphorase-catalyzed reactions. J Agric Food Chem 56:7194-7200 (2008).

43 Papetti A, Daglia M, Grisoli P, Dacarro C, Gregotti C and Gazzani G, Antiand pro-oxidant activity of Cichorium genus vegetables and effect of thermal treatment in biological systems. Food Chem 97:157-165 (2006).

44 Williams DJ, Edwards D, Hamernig I, Jian L, James AP, Johnson SK et al., Vegetables containing phytochemicals with potential anti-obesity properties: a review. Food Res Int 52:323-333 (2013).

45 Morales P, Ferreira ICFR, Carvalho AM, Sánchez-Mata MC, Cámara M, Fernández-Ruiz $\mathrm{V}$ et al., Mediterranean non-cultivated vegetables as dietary sources of compounds with antioxidant and biological activity. LWT - Food Sci Technol 55:389-396 (2014).

46 Spina M, Cuccioloni M, Sparapani L, Acciarri S, Eleuteri AM, Fioretti $\mathrm{E}$ et al., Comparative evaluation of flavonoid content in assessing quality of wild and cultivated vegetables for human consumption. J Sci Food Agric 88:294-304 (2008). 